\title{
Children as Bellwethers of Recovery: Dysfunctional Systems and the Effects of Parents, Households, and Neighborhoods on Serious Emotional Disturbance in Children After Hurricane Katrina
}

\author{
David M. Abramson, PhD; Yoon Soo Park, MS; Tasha Stehling-Ariza, MPH; Irwin Redlener, MD
}

\section{ABSTRACT}

Background: Over 160000 children were displaced from their homes after Hurricane Katrina. Tens of thousands of these children experienced the ongoing chaos and uncertainty of displacement and transiency, as well as significant social disruptions in their lives. The objectives of this study were to estimate the long-term mental health effects of such exposure among children, and to elucidate the systemic pathways through which the disaster effect operates.

Methods: The prevalence of serious emotional disturbance was assessed among 283 school-aged children in Louisiana and Mississippi. These children are part of the Gulf Coast Child \& Family Health Study, involving a longitudinal cohort of 1079 randomly sampled households in the two states, encompassing a total of 427 children, who have been interviewed in 4 annual waves of data collection since January 2006. The majority of data for this analysis was drawn from the fourth round of data.

Results: Although access to medical care for children has expanded considerably since 2005 in the region affected by Hurricane Katrina, more than $37 \%$ of children have received a clinical mental health diagnosis of depression, anxiety, or behavior disorder, according to parent reports. Children exposed to Hurricane Katrina were nearly 5 times as likely as a pre-Katrina cohort to exhibit serious emotional disturbance. Path analyses confirm the roles played by neighborhood social disorder, household stressors, and parental limitations on children's emotional and behavioral functioning.

Conclusions: Children and youth are particularly vulnerable to the effects of disasters. They have limited capacity to independently mobilize resources to help them adapt to stressful postdisaster circumstances, and are instead dependent upon others to make choices that will influence their household, neighborhood, school, and larger social environment. Children's mental health recovery in a postdisaster setting can serve as a bellwether indicator of successful recovery or as a lagging indicator of system dysfunction and failed recovery.

(Disaster Med Public Health Preparedness. 2010;4:(doi:10.1001/dmp.2010.7))

Key Words: recovery, resilience, pediatric, mental health, serious emotional disturbance

$\mathrm{H}$ urricane Katrina precipitated one of the largest population displacements in US history. It has been estimated that as many as $1.5 \mathrm{mil}$ lion people evacuated their homes in the Gulf Coast region as the hurricane approached landfall. ${ }^{1}$ Extending beyond the temporary evacuation, however, was the displacement of individuals and families who left their homes either before or after the storm struck but who were unable to return for months or even years, if they returned at all. Based on US Census reports and school enrollment data from Louisiana and Mississippi, close to 500000 people were displaced for at least 3 months, a figure that included more than 160000 children younger than 18 years. ${ }^{2,3}$ According to Federal Emergency Management Agency (FEMA) data, there were nearly 30000 trailers and mobile homes deployed in congregate settings in the 2 states from 1 to 3 years. ${ }^{4-7}$ Two years after the hurricane, school enrollment in Louisi- ana and Mississippi was still 55000 students below their pre-Katrina rates, and it has been estimated that the present population of New Orleans has reached only 75\% to $80 \%$ of its pre-Katrina levels. ${ }^{8}$ Although a number of families have permanently resettled in other areas, it seems evident that tens of thousands of children remained displaced or unstably housed for years after the initial hurricane.

Numerous reports have documented the challenging circumstances faced by displaced children in the years after Katrina. ${ }^{9-14}$ Although much of the literature on the health implications of disasters has focused on adult populations, there is a growing awareness that disasters affect children in different and important ways. ${ }^{14} \mathrm{Di}$ sasters are potentially far more destructive to children than to adults because they introduce multifaceted stressors at a crucial time of life. ${ }^{15}$ Related events, such as the 
loss of a parent, the loss of home and cherished objects, evacuation from a community, or the disruption of ties to civic institutions such as schools and medical care, can negatively affect a child's physical, mental, and social development. Furthermore, there is evidence that children from low-income families, already at risk for inadequate social and educational development, are affected by a disaster more adversely than are adults. ${ }^{10,12,16}$

In the aftermath of a disaster, children have a limited capacity to independently mobilize resources to help them adapt to the stresses of a catastrophic event and its long-term consequences. Beyond their native attribute of resiliency, children who are trying to adapt to the chaos and uncertainty of their postdisaster circumstances are dependent upon others to make choices that will influence their household, neighborhood, school, and extended social environments. Considerable research in human development and resilience theory has established the roles that these interdependent social systems play in children's development and psychological well-being. ${ }^{17-19} \mathrm{Chil}$ dren's dependence upon these social forces suggests that their recovery from a disaster may in fact reflect larger communal recovery processes. As such, children's recovery may be a bellwether of a population's recovery. If a child's psychological wellbeing reflects the functional health of a number of intersecting social systems, then the "excess" mental health morbidity in a disaster-exposed population — what remains after accounting for predisaster morbidity rates - may represent the product of multisystem dysfunction. Conversely, a return to a normal state of psychological well-being in children may signal the restoration of many of these social systems to a balanced and productive state.

\section{SYSTEMS THEORIES AND CHILDREN'S MENTAL HEALTH}

Bronfenbrenner's ecological model of child development identifies the systems that influence a child's well-being: microsystems within the child (eg, immunological, neurological), mesosystems that have direct influence on the child (eg, families, schools, peer groups), exosystems that have an indirect effect on the child through the intervening mesosystems (eg, parents' workplaces, places of worship), macrosystems (eg, communities at large, political culture), and time-associated chronosystems (eg, normative events such as puberty and high school graduation, nonnormative events such as disasters). ${ }^{20}$ Work in resilience theory and human development has elaborated upon the adaptive processes and mechanisms within children that govern the effects of these systems. These adaptive processes and mechanisms could include children's relationships and attachments to parents or key caregivers, their self-efficacy and self-mastery, and their problem-solving skills, all of which are severely challenged by disasters that disrupt their routine environments and relationships. ${ }^{17,18}$ Family stress theories identify the ways in which families operate as complex adaptive systems to buffer external stresses (eg, disaster, chronic poverty) or internal stresses (eg, a parent's mental illness or disability)..$^{21,22}$
Adopting a broader perspective, community resiliency theory embeds children and families within larger social systems. After a disaster, families within a community are dependent not only upon their own individual assets but also such communitywide "networked adaptive capacities" as social capital, political assets, and trusted information, which help the community adapt to its changing circumstances. ${ }^{23}$ Linking these frameworks is the notion that in terms of a child's welfare, context matters, whether it is the context of family dynamics or household characteristics or the larger social environment of neighborhood and communal institutions.

\section{SERIOUS EMOTIONAL DISTURBANCE}

A number of articles have examined posttraumatic stress disorder (PTSD) in children, although there is tremendous variation in the reported incidence and sustained prevalence of pediatric PTSD over time. Child survivors of a number of disasters, including the 1972 Buffalo Creek (West Virginia) flood, ${ }^{24}$ Hurricane Hugo (1989), ${ }^{25}$ the 1990 missile attacks in Israel, ${ }^{26}$ Hurricane Andrew (1992), ${ }^{27-30}$ the 2001 World Trade Center attacks, ${ }^{31,32}$ and Hurricane Katrina (2005), ${ }^{33}$ have been tested for PTSD. This literature has generally documented proximal PTSD effects within the first year, and a limited number of articles have explored the persistence of PTSD, although rarely more than 2 years beyond the event. Kessler et al have described the trajectory of PTSD prevalence over time as an "inverse Jshape," in which rates drop reasonably quickly after the event and then level off to a chronic stage. ${ }^{34}$ In 1 longitudinal study, Green et al followed child survivors of the 1972 Buffalo Creek flood and found that PTSD rates had fallen from a high of $32 \%$ to $7 \% 17$ years later. ${ }^{24}$ The hallmark symptoms of PTSDreexperiencing the event, experiencing hyperarousal, experiencing emotional numbing, exhibiting avoidance-are measured as they relate to a specific event or phenomenon, which may underestimate more pernicious mental health effects that are not so event specific in their symptomatology or whose origin is a long-standing stressor (eg, disruption of social systems and routines) rather than the short-term event alone. Serious emotional disturbance (SED), a definitional category developed in the early 1990s in response to Congressional interest in funding community mental health services for children and adolescents, encompasses both mental health distress and social, behavioral, or functional impairment, ${ }^{35}$ and may provide a better marker of childhood mental health problems than PTSD. One study to date has reported SED in child and adolescent survivors of Hurricane Katrina. ${ }^{36}$ Based on parent reports 2 years after the hurricane, an overall SED prevalence of $14.9 \%$ in children and youths was reported by the researchers, with considerably higher rates in children with greater exposure to hurricane stressors, with a history of parental psychopathology, or who came from more impoverished households.

Given our interest in examining the long-term mental health effects of Hurricane Katrina on children, we used data from the Gulf Coast Child \& Family Health Study (GCAFH), a longitudinal cohort of Louisiana and Mississippi households ex- 
posed to Hurricane Katrina, to estimate the prevalence of SED in a displaced and greatly affected pediatric population more than 4 years after the event. We examined the independent effect of the disaster on SED (excess morbidity) and analyzed the systemic pathways through which the hypothesized disaster effect operates. In particular, we were interested in the contextual factors influencing children's well-being: the systems represented by parents, households, and neighborhoods and their independent and combined effects on children's mental health.

\section{METHODS}

\section{Sample}

Between January and August 2006, a random sample of 1079 households in Louisiana and Mississippi that had been displaced or affected greatly by Hurricane Katrina was drawn from FEMA lists of congregate settings (including group trailer sites situated in preexisting private mobile home parks, emergency group trailer sites erected by FEMA, and hotels) and census blocks listed on a FEMA damage assessment database as having undergone moderate, comprehensive, or catastrophic damage, as described previously. ${ }^{37}$ Three follow-up rounds of data collection were conducted after the baseline interview within 23,36, and 54 months after the hurricane. By the fourth round of interviews, 116 respondents had died or were institutionally inaccessible, in prison, or residing in nursing facilities. Of the 963 eligible respondents at the last round, $844(87.6 \%)$ were located and reinterviewed.

At the baseline recruitment, 427 (39.6\%) of the households had minor children. Using a Kish sampling strategy, all of the children in the household were enumerated and a single child was selected for recruitment into the longitudinal study. ${ }^{38} \mathrm{At}$ the fourth round, 402 households with children were reinterviewed, among them 283 households with children between 4 and 17 years old. Bias analyses examining differences between respondents who were retained and those lost to follow-up revealed no significant differences in sociodemographic or key health or recovery characteristics.

\section{Data and Measures}

Face-to-face interviews were conducted by trained communitybased interviewers using structured survey instruments approved by Columbia University and Louisiana State University institutional review boards. The key outcome variable estimating SED was the 25-item Strengths and Difficulties Questionnaire (SDQ), ${ }^{35,39-42}$ administered to parents and caregivers in the fourth interview round. As a measure of SED, the SDQ has been validated widely in both US and international populations as a diagnostic screener and an epidemiological tool, with broadly accepted cutpoints and normative bands representing low, medium, and high levels of emotional and behavioral difficulties ${ }^{43-47}$ Notwithstanding its limited use in disaster mental health studies, the SDQ has been applied widely in domestic and international studies of community mental health, incorporated into the National Health Interview Study (NHIS), and used extensively as a clinical screener. ${ }^{40,41}$ The SDQ is composed of 4 subscales that measure distress and impairment, in- cluding a child's emotional problems, hyperactivity, conduct problems, and peer problems, and 1 subscale that measures prosocial behavior. Parents are presented with a series of 25 statements (eg, child is considerate of other people's feelings, often loses his temper, is kind to younger children) and asked whether each is not true, somewhat true, or generally true, and the responses are scored 0 through 2 . The overall scale and subscales are created using summary scores, with cutpoints for "high" levels of difficulty drawn based on US norms. Reliability testing using Cronbach alpha was conducted for study subjects for the overall SDQ (0.872) and the subscales: emotional problems (0.773), conduct problems $(0.730)$, hyperactivity $(0.781)$, peer problems $(0.441)$, and prosocial behaviors $(0.737)$. Independent variables included trended survey items on children's health status, parental coping, and neighborhood safety, replicating those used in the National Survey of Child Health, and parental mental health was assessed using the Mental Component Summary score (MCS, $\alpha=.912$ ) of the Medical Outcome Study's Short Form (version 2). ${ }^{48-50}$

Four levels of contextual effects were tested: child, parental, household, and neighborhood. Child-level variables included a dichotomously classified age variable (4-12, 13-17 years old), sex, race, mental health diagnoses (based on parental reports of clinical diagnoses of depression, anxiety, and behavior disorders preand post-Katrina), and prosocial behavior in the SDQ. The latter was selected as an independent variable even though it is drawn from the SDQ because it characterizes positive aspects of a child's emotional and behavioral functioning. As indicated above, the other 4 SDQ subscales were used in the dependent variable. $\mathrm{Pa}$ rental variables included parental mental health, informal functional social support, ${ }^{51,52}$ sense of community, ${ }^{53}$ and parents' perceived life recovery. ${ }^{54}$ Household variables included housing stability (defined as living in nontransitional housing in which the respondent is confident he or she can remain for $\geq 1$ year), length of time required to secure stable housing post-Katrina, lost income in the household, financial problems securing sufficient food for the household, and a family functioning scale. ${ }^{55}$ Neighborhood variables, based on respondents' reports, included parents' perceived safety of the community and schools for their children, their perception of physical disorder in the neighborhood (eg, vacant or dilapidated buildings, graffiti, broken roadways) and social disorder (eg, evident drug use, prostitution, gang activity). The latter 2 variables were drawn from work by Sampson and colleagues on neighborhood effects on poverty and adolescent delinquency. ${ }^{56,57}$

For scales that did not have defined scoring algorithms, conventional techniques for scale construction were used. Dichotomous items were scored using item response theory (IRT), and confirmatory factor analysis was used for polytomous items. Sense of community, housing characteristics, and family functioning scales were estimated using IRT; likelihood-based statistics for testing IRT models indicated good global fit of the models for each scale. ${ }^{58}$ Neighborhood effects (eg, social disorder, physical disorder), social support, and life recovery used confirma- 
tory factor analysis, and had good model fits based on the cutoff criteria recommended by $\mathrm{Hu}$ and Bentler ${ }^{59}$ with the Tucker-Lewis index near 0.95 and standardized root mean squared residuals $<.08$. For all of the variables, missing data were imputed using multiple chained equations,${ }^{60,61}$ unless governed by preestablished scale construction algorithms.

\section{Analyses}

A $\chi^{2}$ analysis was conducted in 4 rounds of GCAFH data to explore salient trends in stressors and symptoms in children in the study and to test for interstate differences. Following the analysis, a proof-of-concept test was conducted to establish the presence of an independent effect of exposure to the disaster on children's SED. Data from the 2010 GCAFH study $(n=283)$ was merged with 2004 NHIS data $(n=8607)$. Logistic regression equations and structural equation models (SEM) were used to test the relation of exposure to Hurricane Katrina on children's SED as measured by the SDQ. This exploratory analysis provided the equivalent of a retrospective case-control study by comparing children in the GCAFH with similar children before Katrina. Because of the data limitations involved in selecting matching variables from each data set, 4 major factors that may influence a parent's report of a child's current SED were selected: the child's prior mental illness, parental mental health illness or disability, poverty, and exposure to Hurricane Katrina. Race, age, health insurance, and region were used to statistically control for population differences between the GCAFH and NHIS cohorts. Because prior child mental illness was not equivalently measured in both the GCAFH and NHIS cohorts, it was assumed that preexisting mental illness rates were similar, particularly given the population controls being used.

$\chi^{2}$ analyses were then conducted to identify key contextual variables at the child, parental, household, and neighborhood levels associated with the SDQ and 4 of its subscales in the GCAFH cohort, and stepwise regressions and structural equation models were developed to determine the strength and pathways of association with childhood SED. Analyses were conducted using Stata (StataCorp, College Station, TX) and MPlus (Muthén \& Muthén, Los Angeles, CA).

\section{RESULTS}

Although several stressors and symptoms illustrated in Table 1 are decreasing for children over time-for example, $<10 \%$ are

\section{TABLE 1}

\begin{tabular}{|c|c|c|c|c|c|c|c|c|}
\hline \multicolumn{9}{|l|}{ Portrait of Children's Lives Over Time 12} \\
\hline & \multicolumn{2}{|c|}{$\begin{array}{l}\text { Wave 1: Jan-Aug } \\
\quad 2006\end{array}$} & \multicolumn{2}{|c|}{$\begin{array}{l}\text { Wave 2: Apr-Jul } \\
\quad 2007\end{array}$} & \multicolumn{2}{|c|}{$\begin{array}{l}\text { Wave 3: Jun-Sep } \\
\quad 2008\end{array}$} & \multicolumn{2}{|c|}{$\begin{array}{l}\text { Wave 4: Nov 2009-Mar } \\
2010\end{array}$} \\
\hline & LA & MS & LA & MS & LA & MS & LA & MS \\
\hline$\%$ living in trailer/hotel & $100.0^{c}$ & 66.7 & 51.1 & 50.4 & 14.6 & 17.4 & 8.2 & 6.8 \\
\hline$\%$ living with single parent & $57.7^{c}$ & 43.0 & $60.3^{c}$ & 43.9 & $63.9^{c}$ & 43.2 & $61.9^{c}$ & 49.9 \\
\hline$\%$ with pre-existing medical condition & 18.6 & 19.3 & na & na & na & na & na & na \\
\hline$\%$ with newly diagnosed medical condition & na & na & $18.7^{\mathrm{c}}$ & 11.3 & 20.6 & 20.1 & $9.7^{c}$ & 16.9 \\
\hline$\%$ with pre-existing mental health condition & $22.0^{c}$ & 29.0 & na & na & na & na & na & na \\
\hline$\%$ with newly diagnosed mental health condition 34 & na & na & $30.4^{b}$ & 24.5 & 21.9 & 20.9 & 15.7 & 16.9 \\
\hline $\begin{array}{l}\text { \% parents who reported children experiencing current } \\
\text { emotional or behavioral problem }\end{array}$ & na & na & na & na & $45.6^{c}$ & 38.3 & $40.8^{c}$ & 49.1 \\
\hline $\begin{array}{l}\% \text { parents who felt children needed mental health } \\
\text { treatment but did not receive it }\end{array}$ & na & na & na & na & 51.4 & 52.7 & $50.7^{\mathrm{a}}$ & 44.3 \\
\hline$\%$ with medical home & $36.1^{\mathrm{c}}$ & 63.0 & 60.2 & 63.1 & 63.6 & 61.2 & 74.4 & 73.2 \\
\hline$\%$ without health insurance & $9.9^{c}$ & 24.0 & $21.3^{c}$ & 31.5 & $18.5^{\mathrm{c}}$ & 27.3 & $15.2^{c}$ & 24.1 \\
\hline$\%$ with need for specialty medical care & 22.6 & 25.2 & 28.8 & 31.5 & 33.5 & 30.2 & 33.6 & 30.4 \\
\hline$\%$ whose parents are not coping well & 12.6 & 13.5 & $19.2^{\mathrm{b}}$ & 14.9 & 22.6 & 19.4 & 13.2 & 13.1 \\
\hline$\%$ with parents with low mental health (MCS < 42) & 60.6 & 62.0 & 55.1 & 53.0 & $42.0^{\mathrm{a}}$ & 47.2 & $45.1^{\mathrm{a}}$ & 40.0 \\
\hline$\%$ living in households with income $<\$ 10 \mathrm{k}$ & $43.6^{c}$ & 23.8 & $44.4^{c}$ & 31.4 & $36.0^{\mathrm{a}}$ & 30.9 & 33.6 & 29.9 \\
\hline $\begin{array}{l}\% \text { whose parents/caregivers think there are people with } \\
\text { bad influence }\end{array}$ & $67.4^{\mathrm{c}}$ & 56.1 & $59.6^{c}$ & 69.3 & $48.5^{c}$ & 61.9 & $46.9^{c}$ & 58.9 \\
\hline $\begin{array}{l}\% \text { whose parents/caregivers feel children are not safe in } \\
\text { community }\end{array}$ & $46.0^{\mathrm{b}}$ & 52.7 & 47.6 & 44.9 & 37.6 & 38.3 & 41.6 & 41.0 \\
\hline $\begin{array}{l}\text { \% whose parents/caregivers feel children are not safe in } \\
\text { school }\end{array}$ & 25.2 & 24.0 & $38.9^{c}$ & 29.7 & 38.8 & 35.8 & 28.4 & 29.2 \\
\hline$\%$ who moved in prior year & 99.6 & 99.0 & $67.0^{c}$ & 58.3 & 67.2 & 67.0 & $51.3^{c}$ & 59.0 \\
\hline$\%$ child health fair or poor & $12.3^{\mathrm{a}}$ & 9.2 & 23.8 & 24.0 & $18.6^{\mathrm{b}}$ & 24.3 & 14.8 & 14.9 \\
\hline
\end{tabular}

${ }^{1} n=427$ (LA=220, MS=207). Missing data were imputed using multiple imputation by chained equations.

${ }^{2}$ Chi-square significant tests examined differences between states.

${ }^{3}$ Cumulatively, there were $160(\mathrm{LA}=81,36.8 \%$; MS $=79,38.2 \%)$ children out of $427(37.5 \%)$ who have been diagnosed with a mental health condition since Hurricane Katrina according to parental reports. In addition, 128 parents and caregivers (30.0\%) reported that children were still experiencing a problem as of Wave 4.

${ }^{4}$ The denominator of children at risk for newly diagnosed mental health conditions at successive waves excludes children at prior waves who had incident mental health diagnoses. a $p<0.05$

${ }^{\mathrm{b}} p<0.01$

${ }^{c} p<0.001$ 
still living in trailers or hotels 4 years after Hurricane Katrina, the proportion of children living with parents with mental health disability has dropped by more than 15 points since the baseline, and the transiency of children who moved in the prior year has dropped - the overall levels of stressors are higher than national averages. More than $13 \%$ of parents report that they are not coping well with the daily demands of parenting, compared with the national average of $3 \% .{ }^{62}$ Notwithstanding the decline in parents reporting poor mental health, more than $40 \%$ still measure below the cutpoint for mental health distress and disability $(\mathrm{MCS}<42.0)$. In the first year after Hurricane Katrina, $12.3 \%$ of parents in Louisiana and 9.2\% in Mississippi reported that their child's health was fair or poor. This remains virtually unchanged $31 / 2$ years later, with approximately $14 \%$ of parents reporting their child's health status as fair or poor despite the increases in the proportion of children in a "medical home" (defined as consistent and comprehensive pediatric primary care). In the last round of interviews, $40.8 \%$ of parents in Louisiana and $49.1 \%$ in Mississippi reported that their child was experiencing emotional or behavioral problems that they did not experience before Hurricane Katrina. An additional finding in the third round of interviews noted that $32 \%$ of children were at least 1 year behind in age for their grade, a rate that is twice the regional pre-Katrina average (data not shown). At each interview round, parents were asked whether a clinician had discussed with them a new diagnosis of anxiety, depression, or behavioral disorder that had emerged within the past year. (In fact, it should be noted that access to clinical medical services improved during the study period, with $74.4 \%$ of children in pediatric medical homes in the fourth round in Louisiana, compared with only $36.1 \%$ in a medical home at the baseline.) By the second year after the hurricane, 30.4\% of par- ents in Louisiana and 24.5\% in Mississippi reported that clinicians had diagnosed their child as having a mental health condition. Although this measure of new diagnoses diminished in each successive year, there was a cumulative prevalence of diagnosed mental health conditions in more than $37 \%$ of the children (36.8\% in Louisiana, 38.2\% in Mississippi).

In the proof-of-concept analysis, the proportion of parents reporting SED in children in the GCAFH cohort was $36.4 \%$, compared with $8.4 \%$ in the NHIS sample (Table 2). Logistic regression equations revealed that all things being equal, children
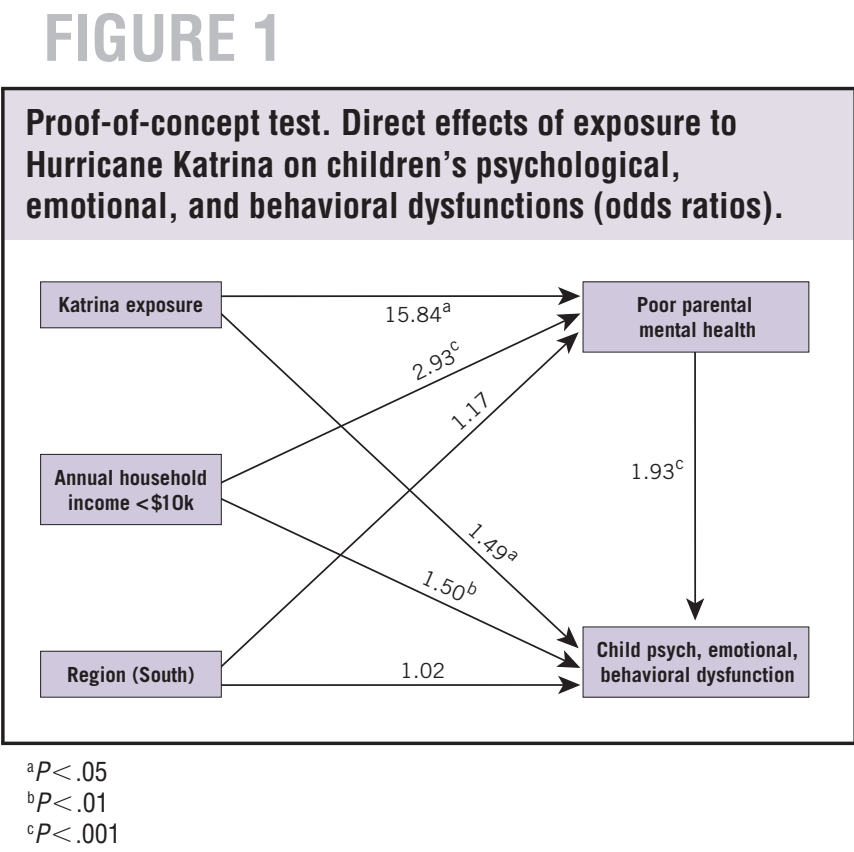

\section{TABLE 2}

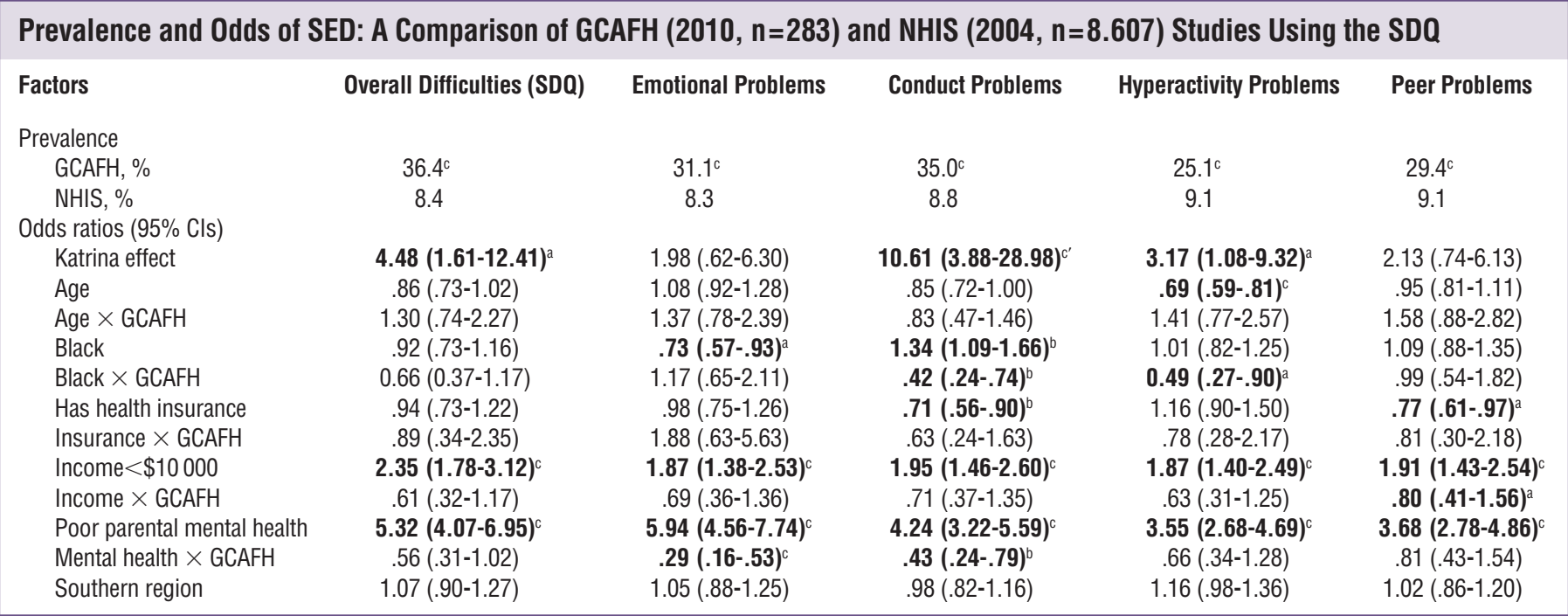

$\mathrm{Cl}=$ confidence interval; GCAFH = Gulf Coast Child \& Family Health Study; NHIS=National Health Interview Study; SDQ=Strengths and Difficulties Questionnaire; SED=serious emotional disturbance.

a $P<.05$

${ }^{\mathrm{b}} P<.01$

${ }^{\mathrm{c} P} P<.001$ 


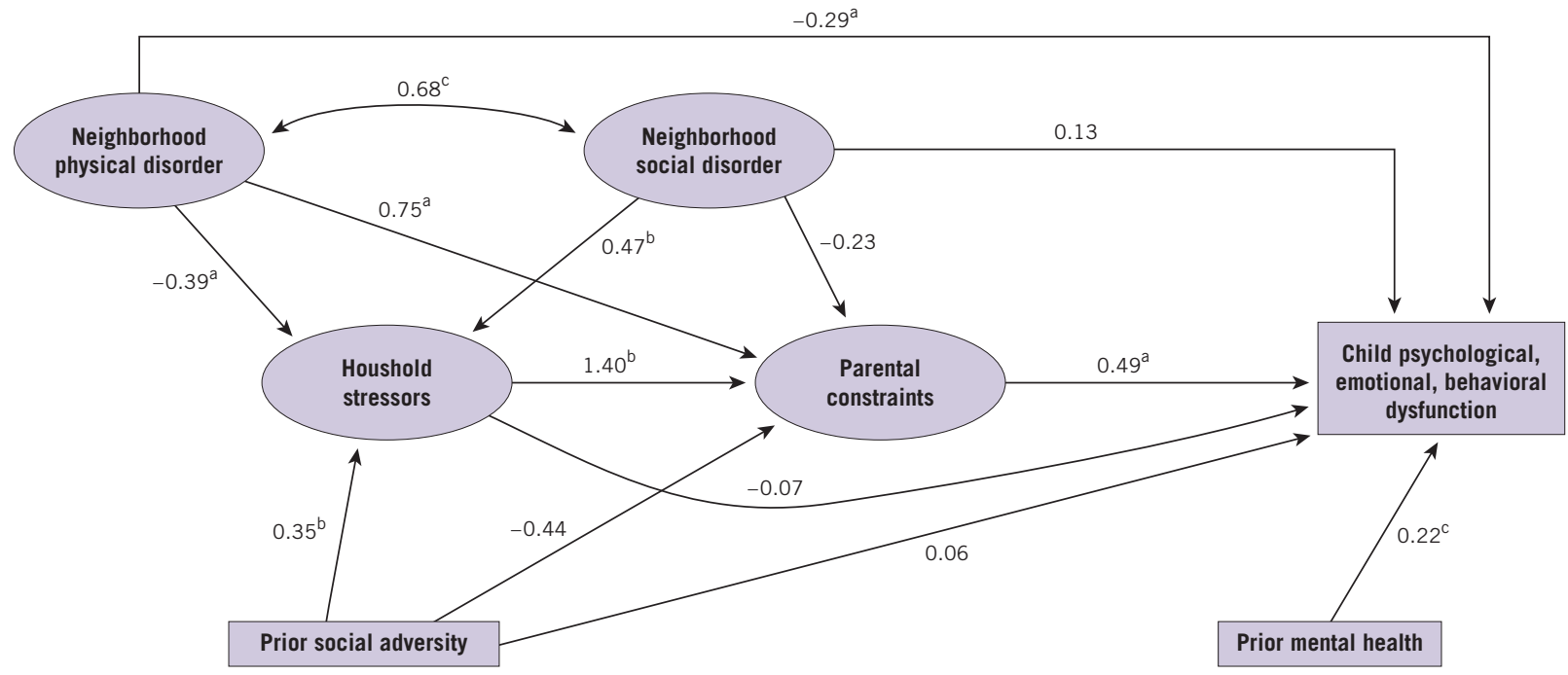

\section{TABLE 3}

\begin{tabular}{|c|c|c|c|}
\hline \multicolumn{4}{|c|}{ Standardized Total and Indirect Effects on SED } \\
\hline & Total Direct & Total Indirect & Total \\
\hline \multicolumn{4}{|l|}{ Figure 1} \\
\hline GCAFH vs NHIS & $1.49^{\mathrm{a}}$ & $2.82^{\mathrm{c}}$ & $4.32^{\circ}$ \\
\hline \multicolumn{4}{|l|}{ Figure 2} \\
\hline Parent & .49 & - & $.49^{a}$ \\
\hline Household & -.07 & $.69^{\mathrm{a}}$ & $.62^{\mathrm{b}}$ \\
\hline Social disorder & .13 & $.19^{b}$ & $.31^{\circ}$ \\
\hline Physical disorder & $-.29^{a}$ & .12 & $-.17^{a}$ \\
\hline Prior social adversity & .06 & .03 & .09 \\
\hline
\end{tabular}

Effect sizes for Figures 1 and 2 in odds ratios and in standardized form, respectively. GCAFH = Gulf Coast Child \& Family Health Study; NHIS= National Health Interview Study; $S E D=$ serious emotional disturbance.

a $P<.05$

${ }^{\mathrm{b}} P<.01$

${ }^{\mathrm{c}} P<.001$

living in poverty were 2.35 times as likely to have SED (95\% confidence interval [CI] 1.78-3.12), those whose parents exceeded mental health disability cutpoints were 5.32 times as likely to have SED (95\% CI 4.10-6.95), and those who were exposed to Katrina were 4.48 times as likely to have SED (95\% CI 1.61-12.41). Similar findings of the effects of parental mental health, poverty, and a "Katrina effect" were found for a number of the subscales. Figure 1 illustrates the structure of direct effects, based on the SEM, which shows that poverty, parental mental health, and the Katrina effect exerted both direct and indirect effects. The total effect of Katrina on child SED is rep- resented by an odds ratio (OR) of 4.32 (Table 3). A little more than one third was contributed directly by exposure to Katrina (OR 1.49, Figure 1) and the remainder operated through parental mental health. The ORs derived in the regression equation, and SEM are similar but not exactly the same because of the different mediating pathways calculated in their respective models.

The bivariate analysis of contextual effects on SED in children in the GCAFH cohort indicated that at the child level, children with prior mental health problems and low levels of prosocial behaviors were more likely to have SED (Overall column, Table 4). At the parental level, poor mental health, low sense of community, and low life recovery scores were associated with the child's SED. At the household level, unstable housing, lost income post-Katrina, the financial stressor of insufficient money for household food, and poor family functioning were associated with SED. At the neighborhood level, parents' perceptions of unsafe schools and communities and their sense of social disorder were also associated with children's SED.

A stepwise regression analysis indicated 2 durable effects on SED at the child level: prior mental health illness or disability and a low score on prosocial behaviors (Table 5). The addition of a parental constraints factor (poor parental mental health, sense of low social support, poor sense of community, and poor sense of recovery) does not explain away the child-level effects, but is independently significantly associated with SED. Household stressors, 
TABLE 4

Familial, Household, and Contextual Factors Associated With SED (GCAFH 2010, $\mathrm{n=283),} \mathrm{Based} \mathrm{on} \mathrm{the} \mathrm{SDQ}$

\begin{tabular}{|c|c|c|c|c|c|}
\hline & $\begin{array}{l}\text { Overall Psychological, Emotional, } \\
\text { and Behavioral Problems, \% }\end{array}$ & $\begin{array}{l}\text { Emotional } \\
\text { Problems, \% }\end{array}$ & $\begin{array}{c}\text { Conduct } \\
\text { Problems, \% }\end{array}$ & $\begin{array}{l}\text { Hyperactivity } \\
\text { Problems, \% }\end{array}$ & $\begin{array}{c}\text { Peer } \\
\text { Problems, \% }\end{array}$ \\
\hline \multicolumn{6}{|l|}{ Child-level variables } \\
\hline \multicolumn{6}{|l|}{ Age, y } \\
\hline $4-12$ & 36.0 & 28.0 & 37.7 & 25.7 & 27.0 \\
\hline 13-17 & 37.0 & 36.1 & 30.6 & 24.1 & 33.3 \\
\hline \multicolumn{6}{|l|}{ Sex } \\
\hline Male & 40.7 & 29.3 & 37.3 & 30.7 & 30.2 \\
\hline Female & 31.6 & 33.1 & 32.3 & 18.8 & 28.6 \\
\hline \multicolumn{6}{|l|}{ Race/ethnicity } \\
\hline Black & 31.5 & 30.3 & $29.7^{\mathrm{a}}$ & $20.0^{\mathrm{a}}$ & 29.9 \\
\hline White & 42.2 & 32.1 & 44.0 & 33.0 & 28.4 \\
\hline \multicolumn{6}{|l|}{ Mental health diagnosis } \\
\hline None pre/none post & $24.9^{c}$ & $21.7^{\mathrm{c}}$ & $28.6^{c}$ & $16.9^{c}$ & $22.3^{b}$ \\
\hline None pre/yes post & 54.2 & 45.8 & 45.8 & 39.6 & 50.0 \\
\hline Yes pre/yes post & 65.2 & 54.4 & 50.0 & 43.5 & 37.0 \\
\hline \multicolumn{6}{|l|}{ Prosocial functioning } \\
\hline Low & $56.5^{\mathrm{c}}$ & 40.3 & $67.7^{\mathrm{c}}$ & $45.2^{c}$ & 40.3 \\
\hline Med & 43.8 & 37.5 & 39.1 & 25.0 & 33.3 \\
\hline High & 25.6 & 24.4 & 20.5 & 17.3 & 23.7 \\
\hline \multicolumn{6}{|l|}{ Parent-level variables } \\
\hline \multicolumn{6}{|l|}{ Parental mental health } \\
\hline Very low (MCS < 37) & $48.0^{\mathrm{b}}$ & 38.7 & 45.3 & 33.3 & $40.0^{\mathrm{a}}$ \\
\hline Low (MCS $37-42)$ & 50.0 & 36.8 & 42.1 & 34.2 & 42.1 \\
\hline Normal (MCS >42) & 28.2 & 26.5 & 28.8 & 19.4 & 21.9 \\
\hline \multicolumn{6}{|l|}{ Social support } \\
\hline Limited & 40.3 & 30.6 & 40.3 & 31.9 & 38.9 \\
\hline Substantial & 35.1 & 31.3 & 33.2 & 22.8 & 26.2 \\
\hline \multicolumn{6}{|l|}{ Sense of community } \\
\hline Low & $43.5^{\mathrm{b}}$ & 35.4 & $41.5^{\mathrm{a}}$ & $29.3^{\mathrm{a}}$ & 32.0 \\
\hline High & 28.7 & 26.5 & 27.9 & 20.6 & 26.7 \\
\hline \multicolumn{6}{|l|}{ Life recovery } \\
\hline Low & $47.4^{\mathrm{b}}$ & $37.7^{\mathrm{a}}$ & $44.7^{\mathrm{a}}$ & $38.6^{c}$ & $37.7^{\mathrm{a}}$ \\
\hline High & 28.1 & 26.2 & 28.7 & 14.6 & 22.7 \\
\hline \multicolumn{6}{|l|}{ Household-level variables } \\
\hline \multicolumn{6}{|l|}{ Housing stability } \\
\hline Unstable & $45.5^{\mathrm{a}}$ & $37.2^{\mathrm{a}}$ & 40.5 & 29.8 & $38.0^{\mathrm{a}}$ \\
\hline \multirow{2}{*}{\multicolumn{6}{|c|}{ Years to stable housing }} \\
\hline & & & & & \\
\hline Immediate & 25.0 & 25.0 & 25.0 & 21.9 & 9.4 \\
\hline $1-2$ & 30.6 & 27.8 & 27.8 & 16.7 & 22.9 \\
\hline $3-4$ & 31.2 & 26.9 & 34.4 & 23.7 & 28.0 \\
\hline Still unstable & 45.5 & 37.2 & 40.5 & 29.8 & 38.0 \\
\hline \multicolumn{6}{|l|}{ Lost income } \\
\hline No income & $48.3^{\mathrm{b}}$ & $46.7^{\mathrm{a}}$ & 43.3 & 30.0 & $45.0^{b}$ \\
\hline Lost income & 53.9 & 42.3 & 50.0 & 38.5 & 42.3 \\
\hline No loss & 30.5 & 24.9 & 30.5 & 21.8 & 23.0 \\
\hline Problems getting food & & & & & \\
\hline No & $32.9^{b}$ & 28.2 & $30.6^{a}$ & 22.2 & 26.5 \\
\hline Yes & 48.5 & 40.9 & 48.5 & 34.9 & 39.4 \\
\hline Family functioning & & & & & \\
\hline Low & $45.5^{\mathrm{a}}$ & 38.2 & 43.6 & 30.0 & 34.6 \\
\hline High & 30.6 & 26.6 & 29.5 & 22.0 & 26.2 \\
\hline Neighborhood-level varia & & & & & \\
\hline Community and school sa & & & & & \\
\hline Unsafe & $44.9^{c}$ & $39.0^{\mathrm{a}}$ & $43.2^{\mathrm{a}}$ & $29.7^{\mathrm{a}}$ & 33.9 \\
\hline Safe & 28.8 & 23.2 & 28.8 & 20.0 & 22.6 \\
\hline Physical order & & & & & \\
\hline Less of problem & 34.8 & 29.2 & 33.7 & 25.8 & 28.8 \\
\hline Problematic & 39.1 & 34.3 & 37.1 & 23.8 & 30.5 \\
\hline Social order & & & & & \\
\hline Less of problem & $30.2^{\mathrm{a}}$ & $25.8^{\mathrm{a}}$ & 30.8 & 23.9 & 26.0 \\
\hline Problematic & 44.4 & 37.9 & 40.3 & 26.6 & 33.9 \\
\hline
\end{tabular}

Proportion scoring at "high" levels of behavioral, psychological, or emotional difficulties, at scores $\geq 16$ in the overall SDQ, and scores $\geq 5$ in emotional, $\geq 4$ in conduct, $\geq 7$ in hyperactivity, and $\geq 4$ in peer problem domains. GCAFH=Gulf Coast Child \& Family Health Study; MCS=Mental Summary score; NHIS=National Health Interview Study; SDQ=Strengths and Difficulties Questionnaire; SED =serious emotional disturbance.

${ }^{\mathrm{a}} P<.05$

${ }^{\mathrm{b}} P<.01$

${ }^{c} P<.001$ 
including housing stability and years to stable housing, are statistically significant in an unadjusted model but are explained away in models that include parental constraints. In the full model, which includes the neighborhood effects of physical disorder and social disorder, there are strong effects on a child's SED of social disorder (OR 3.30), low prosocial behavior (OR 0.27), and prior mental health disability in children (OR 6.26), and weaker effects of parental constraints and physical disorder. The direction of physical disorder is counterintuitive: the greater the perceived physical disorder in the neighborhood, the lower the child's SED. All of the other effects are in a direction that is consistent with theory. The SEM decomposition of effects reveals a more nuanced pathway of effects, essentially establishing the cascading influence of factors at multiple levels on children (Figure 2). Prior social adversity (measured as pre-Katrina household income levels below the poverty line) has a direct effect on household stressors in a post-Katrina environment, as does neighborhood social disorder. They exert a combined effect on parents, which in turn influences a child's SED. In subsequent paths, although prior social adversity is not associated with a total effect on child SED (Table 3), social disorder does exert a significant total effect on SED by operating through parental constraints. As would be expected, a child's prior mental health diagnosis is also directly related to current SED. The goodness of fit statistics reported in Table 6 suggest that the model encompassing all of these contextual effects is robust, and that the pathways are correctly specified for this data set.

\section{COMIMENT}

The cause of mental distress and disability in children is often complex, potentially driven by organic factors, social factors, or both. This analysis seeks to understand the long-term mental health effects of a particular disaster upon children by examining the experiences of a cohort of displaced and greatly affected children, with a specific emphasis on the social factors. Broadly speaking, we considered that children's mental health problems could be a function of the effects of Katrina and its subsequent stressors; predisposing factors within the child, such as preexisting mental health issues; or prior social and economic adversities that existed before Katrina. The findings reported above suggest that a considerable proportion of childhood mental health problems, as expressed by SED, could be explained by the direct and indirect effects of Katrina. To the greatest extent possible, given the limitations of our data, we attempted to control for predisposing factors within the child as well as prior social adversity.

The mechanisms we considered began with the assumption that Hurricane Katrina may have had a direct effect on a child as a traumatizing event that threatened the child's sense of control, safety, or stability. Indirectly, the hurricane may have a mediating effect on the child through a variety of factors: neighborhood disruptions and stressors (eg, newly unsafe communities or schools, physical or social disorder on the block), which may operate by limiting a child's opportunities for safe and/or productive social interactions or contributing to the child's sense of instability and insecurity; through household disruptions and stressors (eg, displacement, transiency, poor family functioning, economic stressors), which may limit a child's opportunities or increase their sense of instability; or through parental constraints (eg, parental mental health problems, parents' negative sense of their place within their community, limited parental sense of recovery), which may influence a child's parental support and stability and exacerbate a child's feelings of isolation.

Considering mechanisms that go beyond a "disaster effect," it is possible that a child may be predisposed to having mental health problems after Katrina as a direct effect of earlier (preKatrina) mental health problems. Mental health effects seen

\section{TABLE 5}

\begin{tabular}{|c|c|c|c|c|c|}
\hline Factors & Unadjusted & Model 1 & Model 2 & Model 3 & Model 4 \\
\hline \multicolumn{6}{|l|}{ Child-level variables/moderators } \\
\hline Age (13-17 vs 4-12 y) & 1.05 & 0.80 & 0.73 & 0.76 & 0.71 \\
\hline Sex (male vs female) & 1.49 & 1.32 & 1.33 & 1.29 & 1.23 \\
\hline Race/ethnicity (black vs other) & 0.64 & $0.55^{\mathrm{a}}$ & 0.60 & 0.59 & $0.51^{\mathrm{a}}$ \\
\hline Clinical mental health diagnosis before Katrina & $4.21^{\mathrm{c}}$ & $4.96^{\mathrm{c}}$ & $5.49^{c}$ & $5.46^{c}$ & $6.26^{c}$ \\
\hline Prosocial behaviors & $0.34^{b}$ & $0.31^{\mathrm{c}}$ & $0.31^{c}$ & $0.31^{c}$ & $0.27^{c}$ \\
\hline Household income $<\$ 10000$ at baseline & 1.11 & 1.38 & 1.29 & 1.22 & 1.15 \\
\hline \multicolumn{6}{|l|}{ Contextual effects } \\
\hline Parental constraints factor score & $3.25^{c}$ & - & $3.32^{\mathrm{c}}$ & $3.00^{c}$ & $2.64^{\mathrm{b}}$ \\
\hline Household stressors factor score & $2.00^{\mathrm{b}}$ & - & - & 1.44 & 1.40 \\
\hline Physical disorder in the neighborhood & 1.20 & - & - & - & $0.42^{\mathrm{a}}$ \\
\hline Social disorder in the neighborhood & $1.84^{\mathrm{a}}$ & - & - & - & $3.30^{\mathrm{b}}$ \\
\hline
\end{tabular}

Percentage scoring $\geq$ in $16 \mathrm{SDQ}$. Among the contextual effects, the parental constraints factor score includes parental mental health, sense of informal social support, sense of community, and self-reported life recovery. The household stressors factor score includes current housing stability and years to stable housing, income loss, insufficient funds for household food, and family functioning styles. GCAFH=Gulf Coast Child \& Family Health Study; SDQ=Strengths and Difficulties Questionnaire; SED=serious emotional disturbance.

${ }^{\mathrm{a}} P<.05$

${ }^{\mathrm{b}} P<.01$

${ }^{\mathrm{c} P}<.001$ 
after a disaster may reflect earlier processes or exacerbations of these preexisting mental health problems. Another preexisting condition that could affect a child's mental health in a postdisaster environment is that the child may have been exposed to pre-Katrina social adversity that led to the neighborhood disruption, household disruption, or parental constraints that contributed to the child's social, emotional, or behavioral issues.

These findings established the presence of persistent stressors and symptoms in children who were displaced or greatly affected by the hurricane. The analysis contrasting SED in the GCAFH and NHIS cohorts reveals the magnitude of the mental health problem in disaster-exposed children: more than one third of the exposed children register as having SED, more than 4 times as prevalent as in a pre-Katrina cohort even after controlling for such compelling factors as parental mental disability and social adversity. This proof-of-concept analysis affirmed the presence of a disaster exposure "black box," some set of social, biological, and psychological interactions that led to mental health effects. Moreover, this analysis suggests the magnitude of "excess" pediatric mental health morbidity in a disaster-exposed population. The OR of 4.48 reported in Table 2 nominally represents that children exposed to Katrina (the GCAFH cohort) are nearly 5 times as likely as other children, all things being equal, to have SED. It may also be regarded as a multiplier effect-the disaster "multiplies" the chances of SED nearly 5 -fold. The closer this metric is to 1 , the nearer the group is to predisaster SED rates. If one could compare similar cohorts across different disasters or compare the same cohort over time, then one could determine whether this multiplier effect is lessening (implying a move toward recovery and predisaster rates) or increasing (and suggesting less recovery). Even within this analysis, the range of population values within the $95 \%$ $\mathrm{CI}$ extends from 1.61 to 12.41 , suggesting that some groups are close to predisaster rates, whereas others are distant from recovery. This offers the first suggestion of pediatric mental health recovery as a bellwether measure.

The subsequent regressions and SEM within the GCAFH data offer the second step in considering this bellwether measure. These analyses sought to explain some of the internal processes of this black box, focusing on 3 specific mesosystems that influence a child's mental health - the parents, the larger household, and the neighborhood. The decomposition of effects illustrated the ways that some of the higher-order levels, such as neighborhoods and households, contribute to and operate through parents. To a great extent, these systems were each dysfunctional and each contributed to a sense of instability and uncertainty in a child's life: unsafe neighborhoods and schools, homes beset by economic and housing insecurity, and parents hampered by their own psychological and emotional challenges. Although many of these problems exist in any number of impoverished or embattled communities in the United States, these analyses suggest that the magnitude and force of these distinct and interrelated system failures is both directly and indirectly affected by Katrina and its aftermath. This represents the second key step in the bellwether measure, a consideration that pediatric mental health is a product of multiple systems.

These analyses have a number of limitations that are worth noting. First, the systems studied do not include higher-order exosystems and macrosystems (broader characteristics of civic and social institutions, or economic and policy environments, that could have a trickle-down effect on children), and those systems under observation have been subjectively described by a single reporter, the parent. Second, these data reflect a single, relatively unusual disaster. The long-term displacement that occurred after Hurricane Katrina on such a massive population scale was a rare occurrence in recent domestic history. Such population shifts and forced migrations are not uncommon in theaters of conflict or natural hazards in resource-poor countries, but it would be difficult to generalize from those countries' systems to those extant in resource-rich countries.

\section{CONCLUSIONS}

Clearly, the systems that regulate a child's welfare remain in flux long after the initial exposure to a disaster. As is evident in this analysis, systems of parental control, household functioning, and neighborhood stability each play a role in contributing to a child's well-being, and each of these systems is still engaged in its own trajectory of recovery. All together, these systems, particularly when dysfunctional or less than optimal, contribute to the stresses experienced by children. Shonkoff et al have written about the effects of "toxic stresses," prenatal and childhood exposures that lead to a variety of cardiovascular, endocrinological, and neurological disorders that are expressed much later in life. ${ }^{63}$ Among Shonkoffs objectives is to understand how poverty "gets under the skin."

\section{TABLE 6}

\begin{tabular}{|c|c|c|}
\hline \multicolumn{3}{|c|}{ Goodness of Fit Statistics and Standardized Factor Loadings } \\
\hline & Figure 1 & Figure 2 \\
\hline \multicolumn{3}{|l|}{ Fit statistics } \\
\hline RMSEA & .00 & .04 \\
\hline SRMR or WRMR & .02 & .05 \\
\hline $\mathrm{CFI} / \mathrm{TLI}$ & $1.00 / 1.00$ & $.93 / .91$ \\
\hline \multicolumn{3}{|l|}{ Factor loadings } \\
\hline \multicolumn{3}{|l|}{ Parent } \\
\hline Mental health & & $.43^{c}$ \\
\hline Sense of community & & $.53^{c}$ \\
\hline Life recovery & & $.53^{\mathrm{c}}$ \\
\hline Social support & & $.28^{\mathrm{c}}$ \\
\hline \multicolumn{3}{|l|}{ Household } \\
\hline Years to stable housing & & $.34^{c}$ \\
\hline Family functioning & & $.29^{c}$ \\
\hline Lost income & & $.19^{c}$ \\
\hline Food problem & & $.19^{c}$ \\
\hline Housing stability & & $.31^{\mathrm{c}}$ \\
\hline
\end{tabular}

$\mathrm{CFI}=$ Bentler Comparative Fit Index; RMSEA=root mean square error of approximation; SRMR=standardized root mean square residual; TLI=Tucker-Lewis Index; WRMR $=$ weighted root mean square residual.

${ }^{a} P<.05$

${ }^{\mathrm{b}} P<.01$

$P<.001$ 
Disasters and their chaotic aftermath can mimic or exacerbate the loss of access to social resources common in poverty. Even on a most immediate level, the consequences of the persistent stress of disasters compounded by prolonged displacement can disrupt academic continuity, itself a potential cause of exacerbated psychological impact.

Shonkoff and colleagues have hypothesized 2 principal mechanisms by which toxic stresses are internalized: as cumulative effects that degrade the body's ability to adapt to stresses, and as acute effects that stress the body's systems at key developmental stages. The latter has greater salience in reference to disaster aftermaths, particularly in children who have lost social resources, whereas the former may be more relevant for those children who live in chronic poverty and for whom the disaster extends the accumulation of stresses, potentially pushing them above thresholds that may be toxic. Regardless of the mechanism, the longterm effects of such toxic stresses, and in this case of a disaster's toxic stresses, remain to be elucidated, particularly in a way that is amenable to mitigation or prevention.

In the aftermath of a disaster, reliable measures of recovery are essential for planners and policymakers who are interested in monitoring the restoration of a community's economic and social productivity. As a bellwether indicator, an aggregate measure of children's positive mental health after a disaster could suggest that multiple social systems are returning to normal; as a lagging indicator, the same aggregate measure of children's negative mental health suggests that these multiple systems are still dysfunctional, in part or as a whole. The results of this analysis would lead the reader to infer that if children are bellwethers of recovery, then the social systems supporting affected Gulf Coast populations are still far from having recovered from Hurricane Katrina.

Author Affiliations: The authors are with the National Center for Disaster Preparedness, Columbia University Mailman School of Public Health.

Published Online: August 23, 2010. doi:10.1001/dmp.2010.7

Correspondence: Address correspondence and reprint requests to Dr David Abramson, Director of Research, National Center for Disaster Preparedness, Columbia University Mailman School of Public Health (e-mail: dma3@columbia .edu).

Received for publication: Received for publication July 15, 2010; accepted July 23, 2010.

Authors' Disclosures: The authors report no conflicts of interest.

Funding for this study was provided by the Children's Health Fund.

Acknowledgments: The authors gratefully acknowledge the participation of the Gulf Coast residents in our ongoing study; their interest and enthusiasm is a testament to their recovery and resilience. Additionally, the authors wish to thank our partners at the Louisiana State University School of Public Health, Drs. DeAnn Gruber, PhD MSW, and Stephanie Tortu, PhD; the project directors who have coordinated the field teams, Barbara Bennet, Catherine Trimbur, and Jyaphia Christos-Rodgers; project staff Akilah Banister MPH and Jonathan Sury MPH; and the many dedicated field team captains and interviewers.

\section{REFERENCES}

1. Wolshon B, McArdle B. Temporospatial analysis of Hurricane Katrina regional evacuation traffic patterns. J Infrastruct Syst. 2009;15:12-20.

2. Abramson D, Redlener I, Stehling-Ariza T, Fuller E. The Legacy of Katrina's Children: Estimating the Numbers of At-Risk Children in the Gulf Coast States of Louisiana and Mississippi. NCDP Research Brief 2007_12. New York: National Center for Disaster Preparedness, Mailman School of Public Health, Columbia University; 2007. http://hdl.handle.net/10022 /AC:P:8845, Accessed Aug 6, 2010.

3. US Census Bureau. 2005 Gulf Coast Area Data Profiles. American Community Survey 2006 Feb. 28, 2008]; Available from: http://www.census .gov/acs/www/Products/Profiles/gulf_coast/profiles.htm. Accessed May 30, 2010.

4. Federal Emergency Management Agency. Louisiana: 1603/1607. Individual Assistance Program Global Report. New Orleans: FEMA Gulf Coast Recovery Office; 2008.

5. Federal Emergency Management Agency. Mississippi: 1604. Individual Assistance Program Global Report. New Orleans: FEMA Gulf Coast Recovery Office; 2008.

6. Federal Emergency Management Agency By The Numbers. FEMA/ MEMA Mississippi Recovery Effort Aug. 2008. http://www.fema.gov/news /newsrelease.fema?id=45538. Accessed May 30, 2010.

7. Federal Emergency Management Agency. By The Numbers: FEMA Recovery Update in Louisiana. http://www.fema.gov/news/newsrelease.fema ?id=24505. Accessed May 30, 2010.

8. Plyer A. Hurricane Katrina Impact. April 15, 2010, New Orleans: Greater New Orleans Community Data Center. http://www.gnocdc.org /Factsforfeatures/HurricaneKatrinaImpact/index.html. Accessed May 30, 2010.

9. Abramson D. Garfield R. On The Edge: Children and Families Displaced by Hurricanes Katrina and Rita Face a Looming Medical and Mental Health Crisis. New York: National Center for Disaster Preparedness, Mailman School of Public Health, Columbia University; 2006. http://hdl.handle .net/10022/AC:P:8847, Accessed Aug 6. 2010.

10. Abramson D, Garfield R, Redlener I. The Recovery Divide: Poverty and the Widening Gap Among Mississippi Children and Families Affected by Hurricane Katrina. New York: National Center for Disaster Preparedness, Mailman School of Public Health, Columbia University; 2007. http: //hdl.handle.net/10022/AC:P:8846, Accessed Aug 6, 2010.

11. Costa NM, Weems CF, Pina AA. Hurricane Katrina and youth anxiety: the role of perceived attachment beliefs and parenting behaviors. J Anxiety Disord. 2009;23(7):935-941.

12. Fothergill A, Peek L. Surviving catastrophe: a study of children in Hurricane Katrina. In Learning from Catastrophe: Quick Response Research in the Wake of Hurricane Katrina. Boulder: Institute of Behavioral Science, University of Colorado; 2006. 97-129.

13. Reich JA, Wadsworth M. Out of the floodwaters, but not yet on dry ground: experiences of displacement and adjustment in adolescents and their parents following Hurricane Katrina. Children Youth Environ. 2008;18:354370.

14. Peek L. Children and disasters: understanding vulnerability, developing capacities, and promoting resilience - an introduction. Children Youth Environ. 2008;18:1-29.

15. Weissbecker I, Sephton SE, Martin MB, Simpson DM. Psychological and physiological correlates of stress in children exposed to disaster: Review of current research and recommendations for intervention. Children. Youth and Environments. 2008;18(1):30-70.

16. Anderson WA. Bringing children into focus on the social science disaster research agenda. Int J Mass Emerg Disasters. 2005;23:159-175.

17. Masten AS. Ordinary magic. Resilience processes in development. Am Psychol. 2001;56(3):227-238.

18. Masten AS, Obradović J. Disaster preparation and recovery: lessons from research on resilience in human development. Ecology and Society. 2008; 13(1):9 http://www.ecologyandsociety.org/vol13/iss1/art9/. Accessed August 10, 2010.

19. Luthar SS, Cicchetti D, Becker B. The construct of resilience: a critical 
evaluation and guidelines for future work. Child Dev. 2000;71(3):543562.

20. Bronfenbrenner U. Ecology of the family as a context for human development: research perspectives. Dev Psychol. 1986;22:723-742.

21. Barnett MA. Economic disadvantage in complex family systems: expansion of family stress models. Clin Child Fam Psychol Rev. 2008;11(3): 145-161.

22. Weissman MM, Pilowsky DJ, Wickramaratne PJ, et al; STAR*D-Child Team. Remissions in maternal depression and child psychopathology: a STAR*D-child report. JAMA. 2006;295(12):1389-1398.

23. Norris FH, Stevens SP, Pfefferbaum B, Wyche KF, Pfefferbaum RL. Community resilience as a metaphor, theory, set of capacities, and strategy for disaster readiness. Am J Community Psychol. 2008;41(1-2):127-150.

24. Green BL, Grace MC, Vary MG, Kramer TL, Gleser GC, Leonard AC. Children of disaster in the second decade: a 17-year follow-up of Buffalo Creek survivors. J Am Acad Child Adolesc Psychiatry. 1994;33 (1):71-79.

25. Shannon MP, Lonigan CJ, Finch AJ Jr, Taylor CM. Children exposed to disaster: I. Epidemiology of post-traumatic symptoms and symptom profiles. J Am Acad Child Adolesc Psychiatry. 1994;33(1):80-93.

26. Laor N, Wolmer L, Mayes LC, Gershon A, Weizman R, Cohen DJ. Israeli preschool children under Scuds: a 30-month follow-up. J Am Acad Child Adolesc Psychiatry. 1997;36(3):349-356.

27. Shaw JA, Applegate B, Schorr C. Twenty-one-month follow-up study of school-age children exposed to Hurricane Andrew. J Am Acad Child Adolesc Psychiatry. 1996;35(3):359-364.

28. La Greca A, Silverman WK, Vernberg EM, Prinstein MJ. Symptoms of posttraumatic stress in children after Hurricane Andrew: a prospective study. J Consult Clin Psychol. 1996;64(4):712-723.

29. La Greca AM, Silverman WK. MC. Children experiencing disasters: definitions, Reactions, and predictors of outcomes. In: La Greca AM, Silverman WK, Vernberg EM, Roberts MC, eds. Helping Children Cope with Disasters and Terrorism. Washington, DC: American Psychological Association; 2002:11-33.

30. Vernberg EM, Silverman WK, La Greca AM, Prinstein MJ. Prediction of posttraumatic stress symptoms in children after hurricane Andrew. J Abnorm Psychol. 1996;105(2):237-248.

31. Hoven CW, Duarte CS, Lucas CP, et al. Psychopathology among New York city public school children 6 months after September 11. Arch Gen Psychiatry. 2005;62(5):545-552.

32. Hoven CW, Duarte CS, Mandell DJ. Children's mental health after disasters: the impact of the World Trade Center attack. Curr Psychiatry Rep. 2003;5(2):101-107.

33. Pina AA, Villalta IK, Ortiz CD, Gottschall AC, Costa NM, Weems CF. Social support, discrimination, and coping as predictors of posttraumatic stress reactions in youth survivors of Hurricane Katrina. J Clin Child Adolesc Psychol. 2008;37(3):564-574.

34. Kessler RC, Galea S, Jones RT, Parker HA; Hurricane Katrina Community Advisory Group. Mental illness and suicidality after Hurricane Katrina. Bull World Health Organ. 2006;84(12):930-939.

35. Costello E. The prevalence of SED. J Child Fam Stud. 1998;7:411-432.

36. McLaughlin KA, Fairbank JA, Gruber MJ, et al. Serious emotional disturbance among youths exposed to Hurricane Katrina 2 years postdisaster. J Am Acad Child Adolesc Psychiatry. 2009;48(11):1069-1078.

37. Abramson D, Stehling-Ariza T, Garfield R, Redlener I. Prevalence and predictors of mental health distress post-Katrina: findings from the Gulf Coast Child and Family Health Study. Disaster Med Public Health Prep. 2008;2(2):77-86.

38. Kish L. Survey Sampling. New York: John Wiley \& Sons; 1965.

39. Goodman R, Ford T, Simmons H, Gatward R, Meltzer H. Using the Strengths and Difficulties Questionnaire (SDQ) to screen for child psychiatric disorders in a community sample. Int Rev Psychiatry. 2003;15(1-2):166172.

40. Mark TL, Buck JA. Characteristics of U.S. youths with serious emotional disturbance: data from the National Health Interview Survey. Psychiatr Serv. 2006;57(11):1573-1578.
41. Warnick E, Bracken M, Kasl S. Screening efficacy of theChild Behavior Checklist and Strengths and Difficulties Questionnaire: a systematic review. Child Adolesc Ment Health. 2008;13:140-147.

42. Vostanis P. Strengths and Difficulties Questionnaire: research and clinical applications. Curr Opin Psychiatry. 2006;19(4):367-372.

43. Flouri E, Mavroveli S, Tzavidis N. Modeling risks: effects of area deprivation, family socio-economic disadvantage and adverse life events on young children's psychopathology. Soc Psychiatry Psychiatr Epidemiol. 2010;45 (6):611-619.

44. Kerfoot M, Koshyl V, Roganov O, Mikhailichenko K, Gorbova I, Pottage D. The health and well-being of neglected, abused and exploited children: the Kyiv Street Children Project. Child Abuse Negl. 2007;31(1): 27-37.

45. Costello EJ, Angold A, Burns BJ, Erkanli A, Stangl DK, Tweed DL. The Great Smoky Mountains Study of Youth. Functional impairment and serious emotional disturbance. Arch Gen Psychiatry. 1996;53(12):11371143.

46. Walrath C, dosResi S. Referral source differences in functional impairment levels for children served in the comprehensive comm mental health services program. J Child Fam Stud. 2001;10:385-397.

47. Bourdon K, Goodman R. Rae DS, Simpson G, Koretz DS.The Strengths and Difficulties Questionnaire: U.S. normative data and psychometric properties. J Am Acad Child Adol Psychiatry. 2005;44):557-564.

48. Ware JE Jr, Kosinski M, Keller SD. A 12-Item Short-Form Health Survey: construction of scales and preliminary tests of reliability and validity. Med Care. 1996;34(3):220-233.

49. Ware JE Jr. Improvements in short-form measures of health status: introduction to a series. J Clin Epidemiol. 2008;61(1):1-5.

50. Gill SC, Butterworth P, Rodgers B, Mackinnon A. Validity of the mental health component scale of the 12-item Short-Form Health Survey (MCS12) as measure of common mental disorders in the general population. Psychiatry Res. 2007;152(1):63-71.

51. Litwak E, Silverstein M. Helping networks among the elderly-the role of ethnicity. Gerontologist. 1985;25:141-142.

52. Messeri P, Silverstein M, Litwak E. Choosing optimal support groups: a review and reformulation. J Health Soc Behav. 1993;34(2):122-137.

53. Chavis DM, Wandersman A. Sense of community in the urban environment. Am J Community Psychol. 1990;18:55-81.

54. Tatsuki S. Long-term life recovery processes among survivors of the 1995 Kobe earthquake: 1999, 2001, 2003, and 2005 Life Recovery Social Survey results. J Disaster Res. 2007;2:484-501.

55. Hayashi H. Long-term recovery from recent disasters in Japan and the United States. J Disaster Res. 2007;2(6):413-418.

56. Raudenbush SW, Sampson RJ. Ecometrics: toward a science of assessing ecological settings, with application to the systematic social observation of neighborhoods. Sociol Methodol. 1999;29:1-41.

57. Sampson RJ, Raudenbush SW, Earls F. Neighborhoods and violent crime: a multilevel study of collective efficacy. Science. 1997;277(5328):918-924.

58. Swaminathan H, Hambleton RK, Rogers HJ. Assessing the fit of item response theory model. In: Rao CR, Sinharray S, eds. Handbook of Statistics: Psychometrics Handbook of Statistics: Psychometrics. Amsterdam: Elsevier; 2007: 35: 691-707.

59. Hu L, Bentler PM. Cutoff criteria for fit indexes in covariance structure anaylsys: Conventional criteria versus new alternatives. Struct Equ Modeling. 1999;6:1-55.

60. Royston P. Multiple imputation of missing values: update. Stata J. 2005;5: 188-201.

61. Schafer JL. Multiple imputation: a primer. Stat Methods Med Res. 1999; $8(1): 3-15$

62. US Department of Health and Human Services, Health Resources and Services Administration. National Survey of Children with Special Health Care Needs, Chartbook 2005-2006. http://mchb.hrsa.gov/cshcn05. Accessed August 2, 2010.

63. Shonkoff JP, Boyce WT, McEwen BS. Neuroscience, molecular biology, and the childhood roots of health disparities: building a new framework for health promotion and disease prevention. JAMA. 2009;301(21): 2252-2259. 